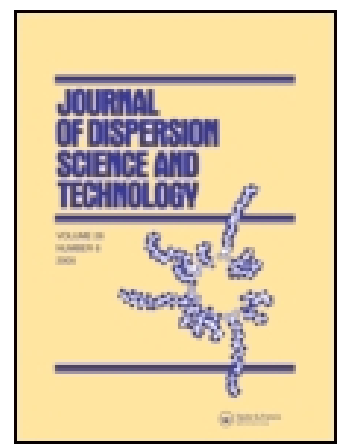

Journal of Dispersion Science and Technology

ISSN: 0193-2691 (Print) 1532-2351 (Online) Journal homepage: http://www.tandfonline.com/loi/ldis20

\title{
Influence of Dispersing Agents on the Solubility of Perovskites in Water
}

\section{Aylin Şakar-Deliormanlı, Erdal Çelik \& Mehmet Polat}

To cite this article: Aylin Şakar-Deliormanlı , Erdal Çelik \& Mehmet Polat (2009) Influence of Dispersing Agents on the Solubility of Perovskites in Water, Journal of Dispersion Science and Technology, 30:5, 704-711, DOI: 10.1080/01932690802553957

To link to this article: http://dx.doi.org/10.1080/01932690802553957

册 Published online: 13 Apr 2009.

Submit your article to this journal $[\pi$

Џ Article views: 40

Q View related articles $\square$

Citing articles: 1 View citing articles 5 


\title{
Influence of Dispersing Agents on the Solubility of Perovskites in Water
}

\author{
Aylin Şakar-Deliormanlı, ${ }^{1}$ Erdal Çelik, ${ }^{2}$ and Mehmet Polat ${ }^{1}$ \\ ${ }^{1}$ Izmir Institute of Technology, Chemical Engineering Department, Urla, Izmir, Turkey \\ ${ }^{2}$ Dokuz Eylul University, Metallurgy and Materials Engineering Department, Izmir, Turkey
}

\begin{abstract}
In this study, solubility behavior of lead magnesium niobate (PMN) powders in water was investigated in the presence of pure polyacrylic acid and polyacrylic acid/polyethylene oxide comb polymers. Experiments were performed by measuring the solubility of PMN in terms of the concentration of $\mathrm{Pb}^{+2}$ and $\mathrm{Mg}^{+2}$ ions in supernatant as a function of $\mathrm{pH}$ and dispersing agent dosage. The concentrations of the metal ions in supernatant were found to be affected by the dispersant concentration, stirring time and the suspension $\mathrm{pH}$. Results revealed that both dispersing agents enhance the cation dissolution from PMN surface at $\mathrm{pH} 9$ due to weak (reversible) adsorption and complexation of $\mathrm{Pb}^{+2}$ and $\mathrm{Mg}^{+2}$ by carboxylate groups. On the other hand, under acidic conditions cation dissolution from PMN is inhibited and this was attributed to the strong adsorption of dispersing agents onto the powder surface and formation of a dense polymer layer.
\end{abstract}

Keywords Anionic polyelectrolyte, ceramics, comb like polymer, solubility, suspensions

\section{INTRODUCTION}

Lead magnesium niobate (PMN) is an important relaxor ferroelectric material with perovskite structure.$^{[1-3]}$ Because of the superior dielectric constant and electrostrictive coefficient it is employed in the manufacture of multilayer ceramic capacitors, actuators, transducers and electrooptic devices. ${ }^{[4,5]}$ It also finds applications in motors, pumps, optical scanning systems, and vibration isolators. ${ }^{[6]}$

The manufacturing of multilayer electronic ceramic devices composed of perovskite materials such as PMN generally involves a colloidal process which requires preparation of stable suspensions. ${ }^{[7]}$ Perovskite materials having the general chemical formula, $\mathrm{ABO}_{3}$ such as $\mathrm{PMN}$ are composed of a cation at the A site that is generally soluble in water and a cation at the B site that is only slightly soluble over the most of the $\mathrm{pH}$ ranges. ${ }^{[8,9]}$ Therefore, the leaching of lead magnesium niobate in water is a major issue in colloidal processing. The nonstoichiometry

Received 4 January 2008; accepted 19 January 2008.

The authors would like to thank Prof. Dr. Jennifer A. Lewis for her support and contributions and Environmental Research Center at Izmir Institute of Technology for use of the ICP-AES. Dynamic light scattering measurements were performed in University of Illinois at Urbana Champaign, Materials Science and Engineering Department. The grant by The Scientific and Technological Research Council of Turkey (Tubitak NATO-A2) is gratefully acknowledged.

Address correspondence to Aylin Şakar-Deliormanlı, Izmir Institute of Technology, Chemical Engineering Department, Urla, 35430 Izmir, Turkey. E-mail: aylindeliormanli@iyte.edu.tr can be induced by leaching of $\mathrm{Pb}^{+2}$ and $\mathrm{Mg}^{+2}$ from PMN surface upon contact with water and this may cause some difficulties in controlling the final dielectric properties and the microstructure. ${ }^{[10]}$ Especially deficiency of lead in PMN structure may cause formation of a undesired phase called pyrochlore which degrades the electrical properties. ${ }^{[11]}$ Therefore, passivation at the PMN/water interface is essential for establishing reliable manufacturing of PMN based ceramic devices.

On the other hand, organic additives such as polyelectrolytes play a significant role in preparation of stable suspensions because they offer an effective means of modifying particle-particle interactions. ${ }^{[12]}$ The polyacrylic acid (PAA) is a widely used polyelectrolyte in ceramic systems. ${ }^{[13-15]}$ It contains ionizable carboxylic acid groups along its backbone. These groups dissociate and form negatively charged carboxylate groups at high $\mathrm{pH}$. Similarly, polyacrylic acid/polyethylene oxide (PAA/PEO) comb polymers can be employed as novel dispersants in ceramic systems. They are very effective stabilizing agents especially for aqueous multi-component metal oxide suspensions such as barium titanate and cement. ${ }^{[16,17]}$ The previous study of Şakar-Deliormanlı et al. showed that PAA/PEO comb polymers are also effective dispersants for PMN/water system. ${ }^{[18]} \mathrm{PAA} / \mathrm{PEO}$ comb polymers impart stability to PMN suspensions over a wide $\mathrm{pH}$ range and ionic strength where pure PAA fails. The presence of PEO teeth shields the PAA backbone from ion interactions. ${ }^{[16]}$

It is known that polymers containing carboxylic acid groups form ionic bonds with the metal surface and this 
reduces the polymer desorption. ${ }^{[19]}$ Kislenko and Verlinskaya showed that polymers containing active functional groups such as PAA can be adsorbed on the zinc oxide, interact with them to form complexes then desorp and thereby increase the zinc ion concentration in solution. ${ }^{[19]}$ Similarly, the effect of anionic dispersing agents on the solubility of kaolin was studied by Zaman and Mathur. ${ }^{[20]}$ They proved that concentration of the aluminum and silicon ions in kaolin suspensions is highly affected by the dosage of the dispersing agents and the slurry $\mathrm{pH}$. Paik and co-workers investigated the effect of polyacrylic acid and polyvinyl alcohol on the solubility of colloidal $\mathrm{BaTiO}_{3}$ in an aqueous medium. They showed that both polymers exhibit passivating tendencies but PAA exhibits both passivation and sequestration (enhancement of solubility) depending on the $\mathrm{pH} \cdot{ }^{[10]}$

Solubility characteristics of bare PMN powders in aqueous medium has been studied studied in the past. ${ }^{[21]}$ Similarly, effect of PAA and PAA/PEO on the dispersion/ flocculation behaviour of aqueous PMN suspensions and their adsorption mechanism onto PMN surface have been well investigated. ${ }^{[18,22]}$ However effect of these dispersing agents on the solubility of PMN was not reported yet. Therefore, the goal of this study was to investigate the influence of PAA and PAA/PEO comb polymers on the stability of $\mathrm{PMN} /$ water interface. In the study $\mathrm{Pb}^{+2}$ and $\mathrm{Mg}^{+2}$ ion leaching from PMN surface was analyzed as a function of dispersing agent concentration, stirring time and suspension $\mathrm{pH}$.

\section{EXPERIMENTAL}

\subsection{Materials}

Lead magnesium niobate, $\mathrm{Pb}\left(\mathrm{Mg}_{1 / 3} \mathrm{Nb}_{2 / 3}\right) \mathrm{O}_{3}$ powder which was produced by combustion spray pyrolysis method provided by Praxair Specialty Ceramics (Woodinville, WA, USA). Powder purity is $99.9 \%$ as reported by the manufacturer. Bulk density (Helium pycnometer Micromeritics 1330, Norcross, GA, USA), and the BET surface area (Model ASAP 2400, Micromeritics, Norcross, GA, USA) of the powder are measured to be $7.967 \mathrm{~g} / \mathrm{cm}^{3}$ and $1.168 \mathrm{~m}^{2} / \mathrm{g}$, respectively. Particle size distribution of the powder was obtained using a particle size analyzer (Model CAPA-700, Horiba, Ltd, Tokyo, Japan) and the $d_{50}$ of the powder was measured to be $2.03 \mu \mathrm{m}$.

Polyacrylic acid graft polyethylene oxide comb polymers PAA/PEO $\left(\mathrm{M}_{\mathrm{w}}: 25800 \mathrm{~g} / \mathrm{mol}\right.$, W.R. Grace and Co. Connecticut, Cambridge, MA) pure PAA $\left(\mathrm{M}_{\mathrm{w}}: 5000 \mathrm{~g} /\right.$ mol, Polyscience Inc., Warrington, PA) were employed as the dispersant for the aqueous PMN suspensions. The comb polymer consists an anionic PAA backbone $\left(\mathrm{M}_{\mathrm{w}}\right.$ : $5000 \mathrm{~g} / \mathrm{mol})$ with ionizable carboxylic acid group $\left(\mathrm{COO}^{-}\right)$ per monomer unit and charge neutral PEO teeth
$\left(\mathrm{M}_{\mathrm{w}}: 2000 \mathrm{~g} / \mathrm{mol}\right)$ grafted onto the backbone at random intervals through ester linkages (acid:ester ratio 7:1). Figure 1 shows the chemical structure of the PAA and PAA/PEO comb polymer used in this study.

\subsection{Method}

\subsubsection{Solution Preparation}

Dilute polymer solutions were prepared by adding an appropriate amount of polymer to deionized water. The $\mathrm{pH}$ was adjusted using either a $0.1 \mathrm{M}$ solutions of $\mathrm{HNO}_{3}$ or $\mathrm{NH}_{3} \mathrm{OH}$. The polymer solutions were magnetically stirred for 0.5 hours to allow for equilibration. $1 \mathrm{M}$ solutions of $\mathrm{KNO}_{3}, \mathrm{MgCl}_{2}, \mathrm{LaCl}_{3}$ were prepared by dissolving $\mathrm{KNO}_{3}, \mathrm{MgCl}_{2} \cdot 6 \mathrm{H}_{2} \mathrm{O}$ (Fisher Chemicals, Fair Lawn, NJ, USA) and $\mathrm{LaCl}_{3}$ (Fisher Chemicals) in deionized water. These salt solutions were used to vary the monovalent, divalent, or trivalent salt concentration of the polymer solutions. To investigate the complexation behavior of $\mathrm{Pb}^{+2}$ with polyelectrolytes, lead(II) acetate trihydrate, $\left(\mathrm{Pb}\left(\mathrm{CH}_{3} \mathrm{COO}\right)_{2} .3 \mathrm{H}_{2} \mathrm{O}, 99.5 \%\right.$, Riedel-de Haen) was used. After adjusting the ionic strength, solutions were magnetically stirred for another 0.5 hours for equilibration.

\subsubsection{Suspension Preparation}

Lead magnesium niobate suspensions were prepared at $10 \mathrm{vol} \%$ in the absence and presence of PAA/PEO comb polymers and PAA. After PMN powder was added to the stock solution of polymeric dispersant, the suspension was ultrasonicated for 2.30 minutes using a $1 \mathrm{~s}$ on/off pulse sequence. The suspension $\mathrm{pH}$ was adjusted using $\mathrm{HNO}_{3}$ and $\mathrm{NH}_{4} \mathrm{OH}$ solutions. Suspensions were magnetically stirred for 24 hours at room temperature prior to measurements.

\subsubsection{Dynamic Light Scattering}

Dynamic light scattering (DLS) measurements (Zetasizer 3000HS, Malvern Instruments Ltd., UK) were carried out on dilute polymer solutions, $(5 \mathrm{mg} / \mathrm{ml}$ and $\mathrm{pH}$ 9) of varying salt concentration to determine their hydrodynamic radius $\left(R_{H}\right)$ as a function of counterion concentration. A refractive index, $n$, of 1.53 , and 1.47 was used during the measurements for PAA and PAA/PEO,

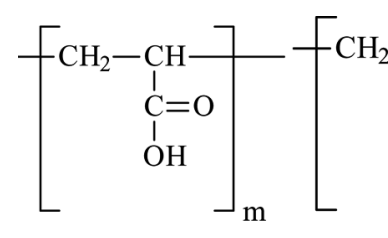

(a)

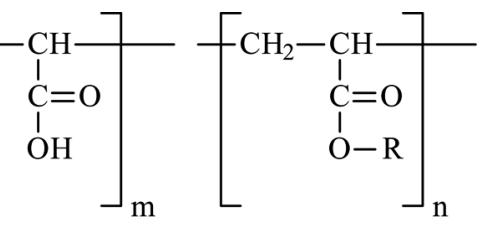

(b)
FIG. 1. Chemical structure of (a) PAA and (b) PAA/PEO comb polymers $\mathrm{R}=\left(\mathrm{CH}_{2} \mathrm{CH}_{2} \mathrm{O}\right)_{\mathrm{x}}-\mathrm{CH}_{3}, \mathrm{x}=45$. $^{[26]}$ 
respectively. The DLS unit utilizes a $\mathrm{He}-\mathrm{Ne}$ laser at a wavelength of $632.8 \mathrm{~nm}$ with a laser power of $10 \mathrm{~mW}$. The scattered light was collected at an angle of $90^{\circ}$. A virgin polystyrene cuvette was used for each measurement.

\subsubsection{Turbidity Measurements}

Dilute polymer solutions $(5 \mathrm{mg} / \mathrm{ml})$ were prepared by adding an appropriate amount of PAA or PAA/PEO comb polymer to deionized water. The turbidity of dilute polymer solutions of varying $\mathrm{pH}$ and salt concentration was measured by a turbidimeter (WTW 555, Germany). Turbidity is an optical property that causes light to be scattered and absorbed rather than transmitted in straight lines through the sample. The turbidimeter used in this study measure the light scattered at an angle to the incident light beam and then relate this angle scattered light to the samples turbidity. ${ }^{[23]}$ Measurements were performed using nephelometric ratio method and results were recorded in terms of NTU with \pm 2 of value or \pm 0.01 NTU accuracy.

\subsubsection{Cation Dissolution}

Solubility of $\mathrm{Pb}^{+2}, \mathrm{Mg}^{+2}$, and $\mathrm{Nb}^{+5}$ ions in the PMN structure was examined using Inductively Coupled Plasma Atomic Emission Spectroscopy (ICP-AES Optima 2000 DV Perkin Elmer Norwalk, CT, USA). For this purpose, suspensions prepared at $10 \mathrm{vol} \%$ according to the procedure described in the previous section were centrifuged at $4000 \mathrm{rpm}$ for 1 hour to obtain a clear supernatant. Supernatants were further filtered from $0.02 \mu \mathrm{m}$ microfilters to eliminate any possible particles in solution. The amounts of $\mathrm{Pb}^{+2}, \mathrm{Mg}^{+2}$, and $\mathrm{Nb}^{+5}$ in particle-free supernatants were determined using ICP-AES at different $\mathrm{pH}$ values and as a function of dispersant concentration.

\section{RESULTS AND DISCUSSION}

\subsection{Hydrodynamic Radius of the Polymers}

Figure 2 shows the hydrodynamic radius $\left(\mathrm{R}_{\mathrm{H}}\right)$ of the PAA/PEO comb polymer and PAA as a function of monovalent and divalent salt additions. The hydrodynamic radius which includes both solvent (hydro) and shape (dynamic) effects provides a measure of the size of the polyelectrolytes in solution. ${ }^{[2]}$ To make comparison between the salt species of having different valency the graph is plotted $\left(\mathrm{R}_{\mathrm{H}}\right)$ versus $[\mathrm{I}] /\left[\mathrm{COO}^{-}\right]$where $[\mathrm{I}]$ is the ionic strength and $\left[\mathrm{COO}^{-}\right]$is the molar concentration of ionized carboxylic acid groups. ${ }^{[16]}$

As it is shown in Figure 2, the hydrodynamic radius values are measured to be 4.9 and $8.0 \mathrm{~nm}$ for PAA and $\mathrm{PAA} / \mathrm{PEO}$, respectively under fully ionized conditions at $\mathrm{pH}$ 9. Results agree with the previous study of Kirby et al. ${ }^{[16]}$ Results also suggest that PAA solution stability changes dramatically as the ionic strength increases. The

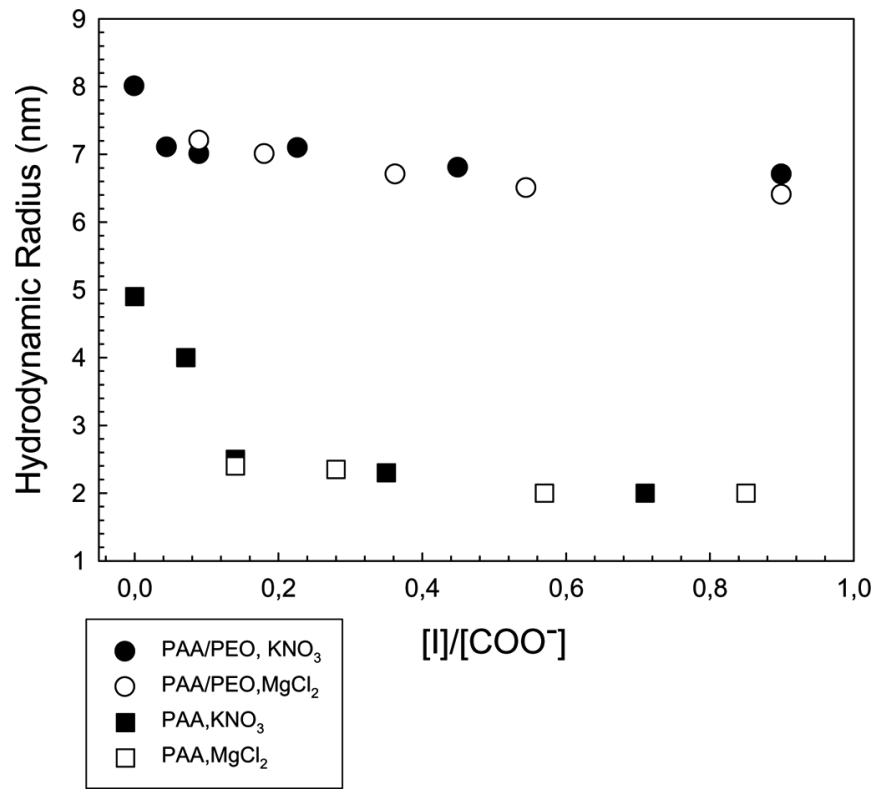

FIG. 2. The hydrodynamic radius of PAA and PAA/PEO solutions as a function of monovalent and divalent salt additions. Where $[\mathrm{I}]=\frac{1}{2} \sum n_{i} z_{i}^{2}$ due to added salt only, $\left[\mathrm{COO}^{-}\right]=0.07$ for PAA, and 0.011 for PAA/PEO.

hydrodynamic radius of PAA reduces to $\sim 2 \mathrm{~nm}$ at high ionic strength conditions. Additionally, both monovalent and divalent salt species do some effect on the transition of PAA to coiled structure. An important characteristic of PAA is its ability to undergo expansion from a coiled to a stretched conformation by the increase in charge density the chain. This transition is due to electrostatic repulsion between neighboring ionized sites. Dissociation of each carboxyl group along the polymer chain significantly affects the ionization of neighboring groups. As a consequence of electrostatic interactions, dissociation becomes difficult as the fraction of ionized sites increases. The effect is analogous to the well-known helix-coil transition that is associated with polypeptides. ${ }^{[14,25]}$

On the other hand, results revealed that stability of PAA/PEO comb polymers is not affected by the salt concentration. Even in the presence of divalent salt species a decrease in the $R_{H}$ was not observed. The different response to ionic strength modification in two polyelectrolytes were attributed to the presence of the PEO teeth in the comb polymer which prevents large conformational changes in ionized conditions.

\subsection{Turbidity Measurements}

Turbidity measurements were carried out on dilute polymer solutions of varying $\mathrm{pH}$ and salt concentration. Figures 3 to 6 show the turbidity values of polymer solutions as a function of ionic strength and $\mathrm{pH}$. The stable polymer solutions characterized in which the polymeric 


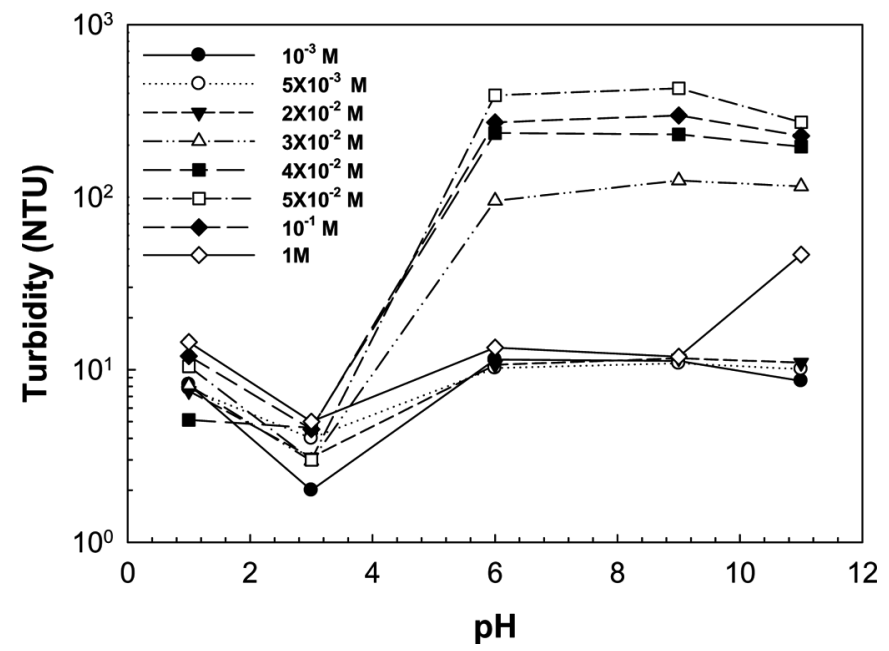

FIG. 3. Effect of $\mathrm{MgCl}_{2}$ concentrations on the turbidity of PAA solutions as a function of $\mathrm{pH}$.

species remain well solvated and are transparent. Therefore, high turbidity values correspond to the solutions having low stability.

As it is shown in Figure 3 in the presence of divalent salt additions $\left(\mathrm{MgCl}_{2}\right)$ the stability of PAA solutions depends on the divalent salt concentration. Under fully ionized conditions ( $\mathrm{pH}$ 9) PAA solutions were only stable in the range $0-2 \times 10^{-2} \mathrm{M} \mathrm{MgCl}_{2}$. At higher salt concentrations PAA start to make complexes with $\mathrm{Mg}^{+2}$ ions in solution and turbidity increases.

Effect of trivalent cations on the stability of PAA and PAA/PEO comb polymer is shown in Figures 4 and 5. Kirby reported that dilute polymer solutions with trivalent, $\mathrm{LaCl}_{3}$ additions could not be prepared above $\mathrm{pH} 7$ due to the precipitation of lanthanum hydroxide that would alter the turbidity results. ${ }^{[2]}$ However, this $\mathrm{pH}$ value is only

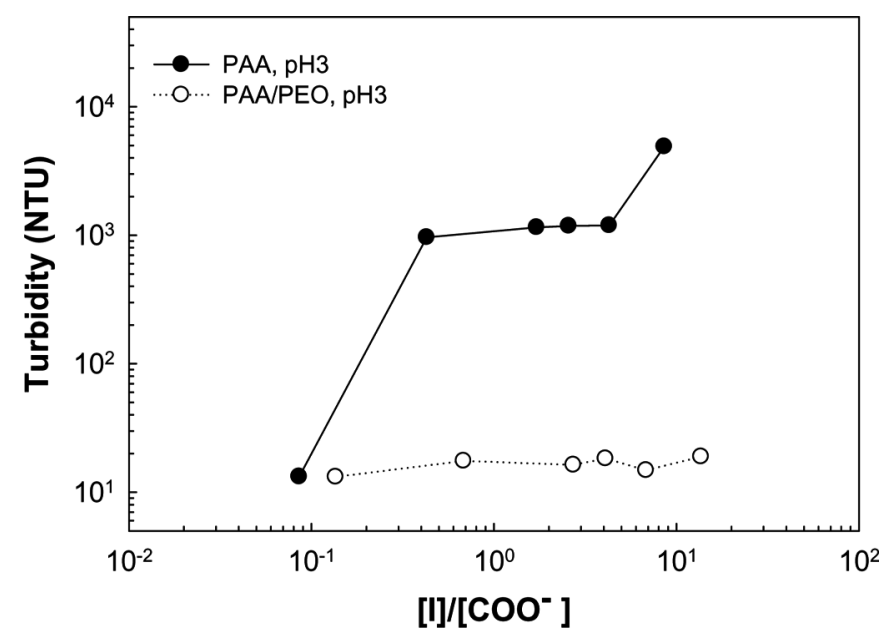

FIG. 4. Effect of $\mathrm{LaCl}_{3}$ on the turbidity of PAA and PAA/PEO solutions at $\mathrm{pH} 3$.

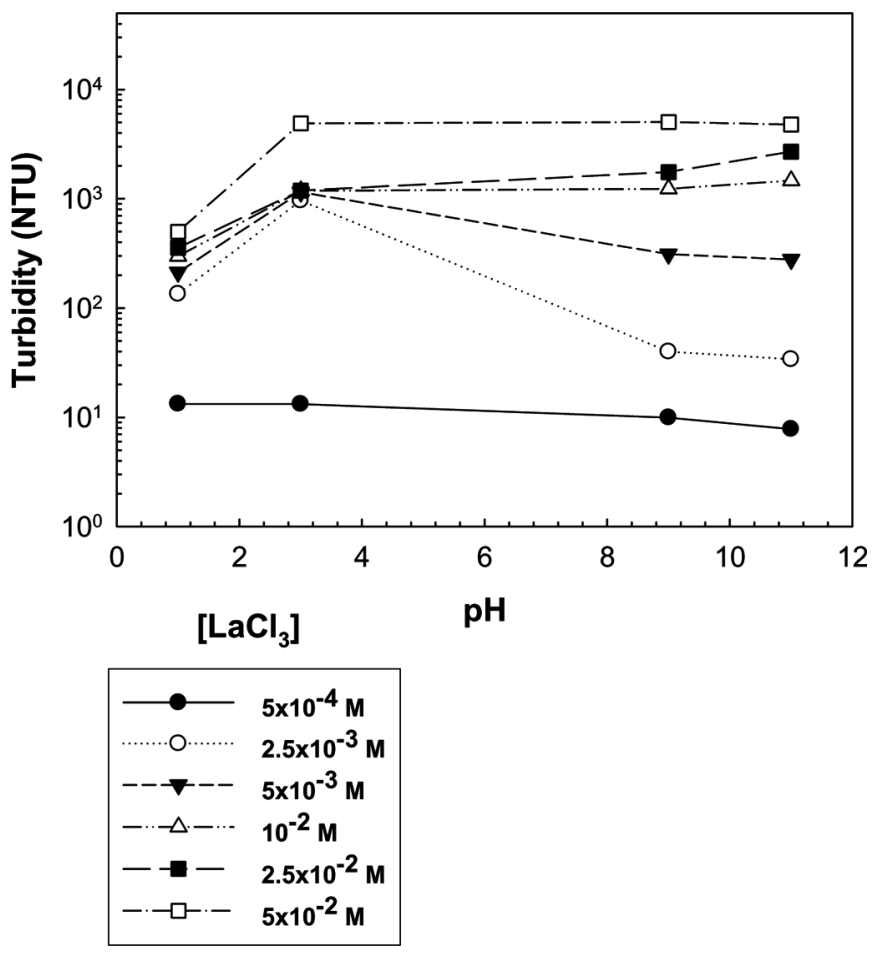

FIG. 5. Effect of $\mathrm{LaCl}_{3}$ concentration on the turbidity of PAA solutions as a function of $\mathrm{pH}$.

slightly below the $\mathrm{pH}$ required for full ionization of the PAA-based species ( $\mathrm{pH} 9$ ). Accordingly, the results of the current work showed that at $\mathrm{pH} 3$ presence of $\mathrm{LaCl}_{3}$ did

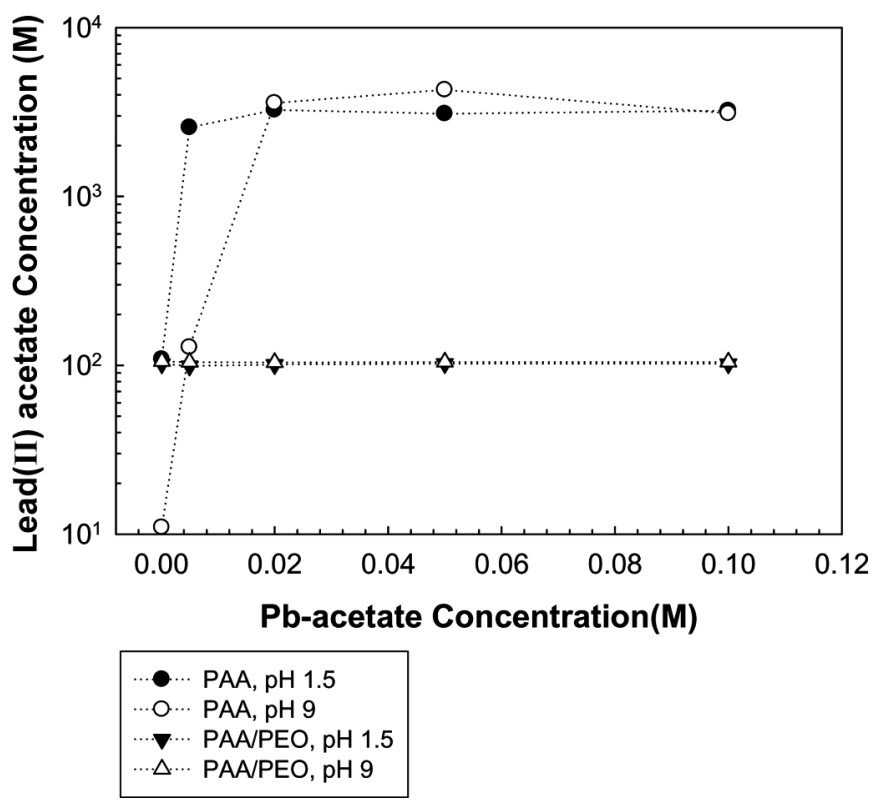

FIG. 6. Effect of lead(II) acetate concentration on the turbidity of PAA and PAA/PEO solutions at pH 1.5 and $\mathrm{pH} 9$. 
not affect the stability of comb polymer solutions. However, a sharp increase was observed in the turbidity of PAA solutions due to PAA- $\mathrm{La}^{+3}$ complexation (see Figure 4). The complex formation initiate at $2.5 \times 10^{-3} \mathrm{M}$ $\mathrm{LaCl}_{3}$ but the maximum turbidity value was obtained at $5 \times 10^{-2} \mathrm{M} \mathrm{LaCl}_{3}$. On the other hand, the increase in turbidity of the PAA/PEO comb polymer solutions at $\mathrm{pH} 9$ in the presence of $\mathrm{LaCl}_{3}$ may be attributed to the precipitation of ions and formation of $\mathrm{La}(\mathrm{OH})_{3}$.

To investigate the interaction of PAA and PAA/PEO comb polymers with the $\mathrm{Pb}^{+2}$ ions in solution, turbidity measurements were performed in the presence of lead(II) acetate. First of all, turbidity of pure lead acetate in water was investigated. It is known that $\mathrm{Pb}$ (II)acetate with water forms $\mathrm{Pb}\left(\mathrm{CH}_{3} \mathrm{COO}\right)_{2} \cdot 3 \mathrm{H}_{2} \mathrm{O}$ which is a colorless crystalline substance. Turbidity of $\mathrm{Pb}(\mathrm{II})$ acetate solution at $5 \times 10^{-2} \mathrm{M}$ started to increase at $\mathrm{pH} 6$ and persist to increase as the $\mathrm{pH}$ increases. Figure 6 show the effect of $\mathrm{Pb}^{+2}$ ion addition on the stability PAA and comb polymer suspensions. Under very acidic and basic conditions no interaction between comb polymer and $\mathrm{Pb}^{+2}$ was observed. On the other hand, even at $\mathrm{pH}<6$ an increase was noticed in the turbidity of PAA solutions in the presence of small amount of lead(II) acetate.

\subsection{Cation Dissolution from PMN in the Presence of Dispersing Agents}

It is known that, $\mathrm{PMN}$ incongruently leach $\mathrm{Pb}^{+2}$ and $\mathrm{Mg}^{+2}$ ions at the interface below $\mathrm{pH} 10$ and therefore the ionic concentration in suspension increases. ${ }^{[21]}$ Especially the $\mathrm{Pb}^{+2}$ concentration increases dramatically in the acidic region. Though the $\mathrm{Mg}^{+2}$ dissolution is also $\mathrm{pH}$ dependent the dissolution rate is almost an order of magnitude smaller compared to that observed with $\mathrm{Pb}^{+2}$ at low $\mathrm{pH}$ values. On the other hand, $\mathrm{Nb}^{+5}$ exhibites rather low dissolution under the same conditions. Dissolution mechanism of cations from PMN surface can be explained as follows: In the first step $\mathrm{Pb}^{+2}$ and $\mathrm{Mg}^{+2}$ must diffuse out through a growing reactive surface layer. In the final stage, dissolution slows considerably and following possibilities may arise: a steady-state equilibrium concentration is reached, a thick the depletion layer may form and leads to passivation; or the particles are completely converted to $\mathrm{Nb}$-rich phase. $^{[21,27]}$

In the current study, the $\mathrm{Pb}^{+2}$ and $\mathrm{Mg}^{+2}$ ion leaching from PMN surface was studied in the presence of PAA and PAA/PEO comb polymers as a function of polyelectrolyte concentration. Experiments were performed for a solids loading of $10 \mathrm{vol} \%$ at different $\mathrm{pH}$ and ionic strength conditions. Figure 7 displays the $\mathrm{Pb}^{+2}$ and $\mathrm{Mg}^{+2}$ ion concentrations of PMN suspensions in the presence of PAA/ $\mathrm{PEO}$ as a function of string time. Results show that $\mathrm{Pb}^{+2}$ and $\mathrm{Mg}^{+2}$ concentration reaches a considerable level immediately after the powder addition and then $\mathrm{Pb}^{+2}$

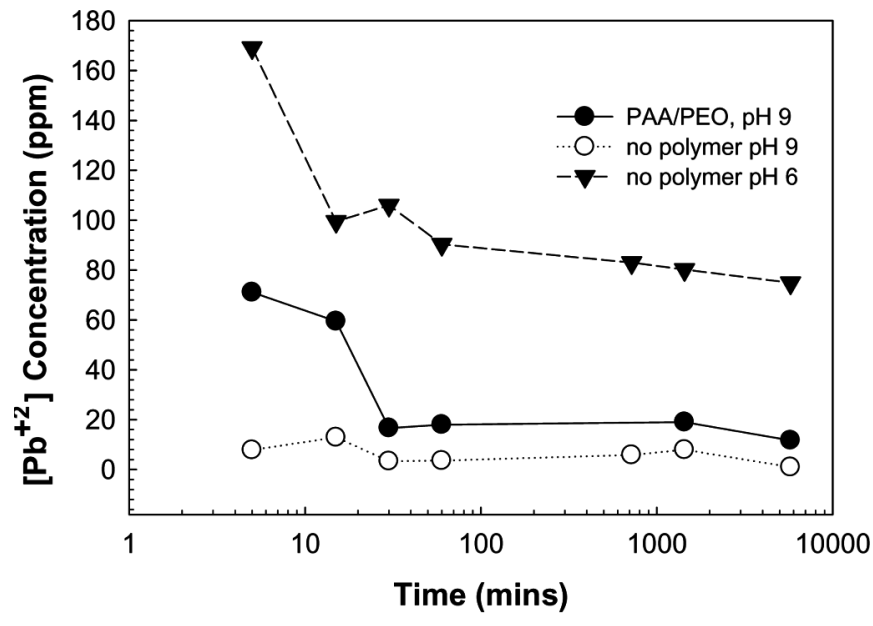

(a)

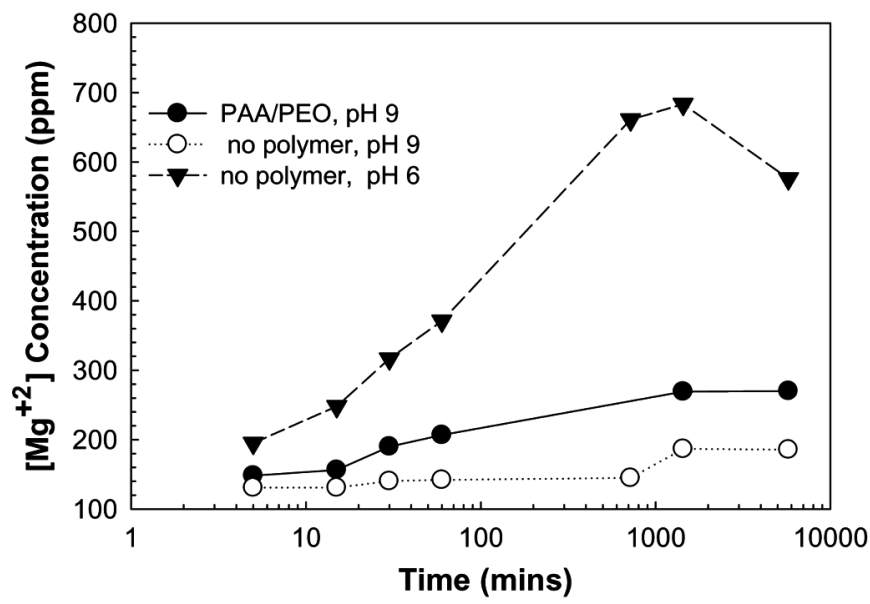

(b)

FIG. 7. Effect of PAA/PEO $(10 \mathrm{mg} / \mathrm{ml})$ on the leaching of (a) $\mathrm{Pb}^{+2}$ and (b) $\mathrm{Mg}^{+2}$ in $\mathrm{PMN}$ suspension $(10 \mathrm{vol} \%$ ) as a function of stirring time.

concentration decreases and $\mathrm{Mg}^{+2}$ concentration increases with time. In the presence of comb polymer $\mathrm{Pb}^{+2}$ concentration in suspension was nearly 10 times higher compared to lead concentration of suspensions in absence of dispersant. Neubrand and co-workers observed similar behavior for $\mathrm{Ba}^{+2}$ dissolution from barium titanate surface as a function time. ${ }^{[28]}$

It is possible to explain the decrease in lead concentration by re-adsorption of $\mathrm{Pb}^{+2}$ ions to the hydrated PMN surface. Surface charge of the PMN is negative at $\mathrm{pH}$ 10. ${ }^{[21]}$ Because of the negative surface charge $\mathrm{Pb}^{+2}$ ions may be re-adsorbed onto the surface and this may cause a decrease in $\mathrm{Pb}^{+2}$ concentrations in solution. Another explanation for the decrease observed in lead amount may due to the complex formation such as $\mathrm{PbOH}$ or $\mathrm{Pb}_{4}(\mathrm{OH})_{4}^{4}$. ${ }^{29]}$

Figures 8 and 9 demonstrate the effect of PAA/PEO comb polymers and PAA on the solubility of PMN as a 


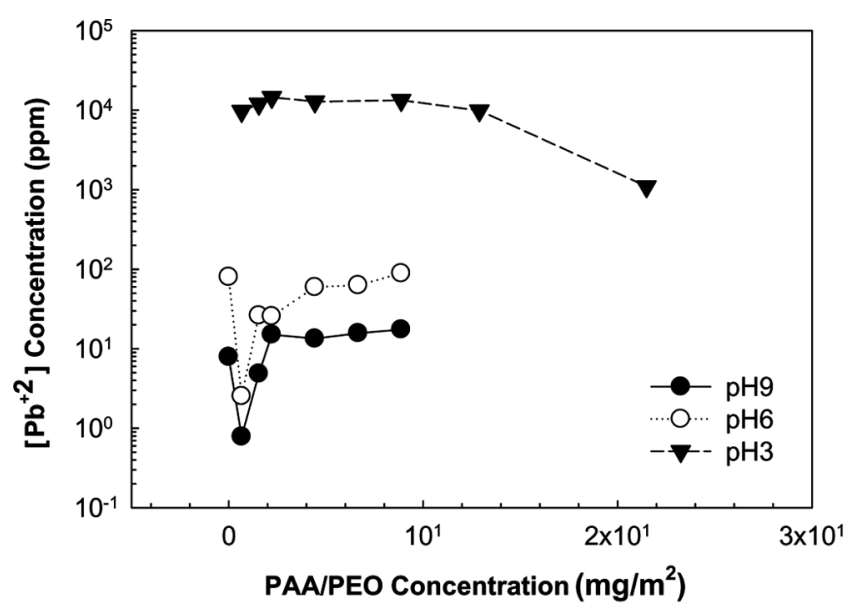

(a)

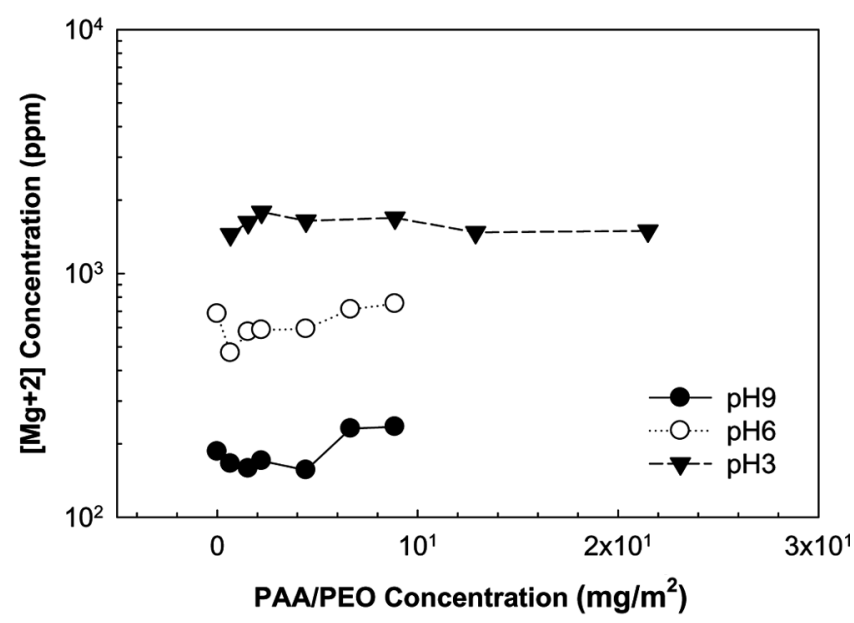

(b)

FIG. 8. Effect of PAA/PEO concentration on the leaching of (a) $\mathrm{Pb}^{+2}$ (b) $\mathrm{Mg}^{+2}$ in PMN suspension (10 vol\%) at $\mathrm{pH} 9,6$, and 3 .

function of polymer concentration and suspension $\mathrm{pH}$, respectively. Both polyelectrolytes enhanced the solubility of $\mathrm{PMN}$ and caused an increase in the $\mathrm{Pb}^{+2}$ and $\mathrm{Mg}^{+2}$ ion concentration in solution at $\mathrm{pH} 6$ and $\mathrm{pH}$ 9. Furthermore, an increase was observed in $\mathrm{Pb}^{+2}$ and $\mathrm{Mg}^{+2}$ concentrations in solution as the polyelectrolyte concentration increase.

Paik and coworkers investigated the effect of PAA on the solubility of barium titanate in aqueous medium. Results showed that $\mathrm{Ba}^{+2}$ sequestered by PAA in solution at basic $\mathrm{pH}$ values. At $\mathrm{pH} 8$ and higher where PAA is well dissociated and the adsorption is low and the polymer enhanced the dissolution of $\mathrm{Ba}^{+2}$. They attributed this result to the complex formation in solution but it may also involve adsorption of PAA as an initial step. ${ }^{[10]}$ On the other hand, at acidic $\mathrm{pH}$ values where PAA adsorption is largely irreversible PAA causes passivation and this effect increases polymer concentration. Therefore, when

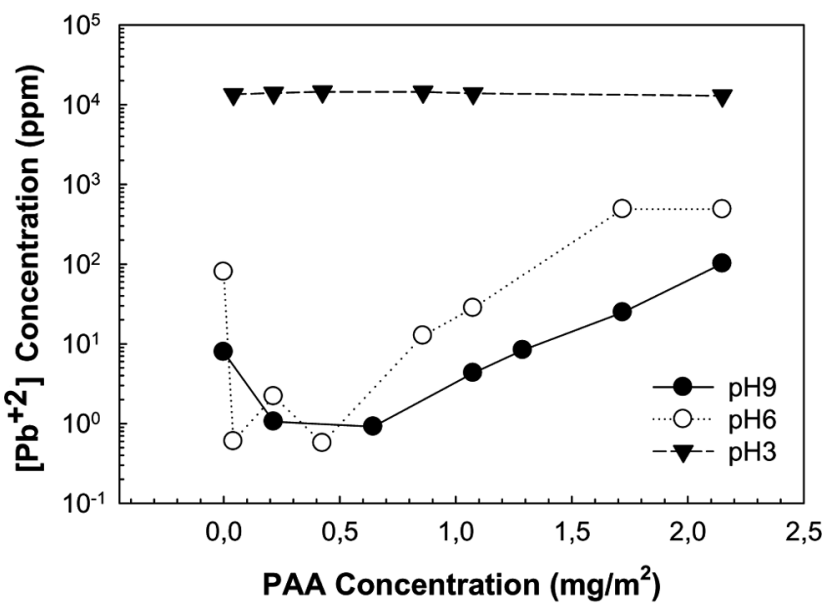

(a)

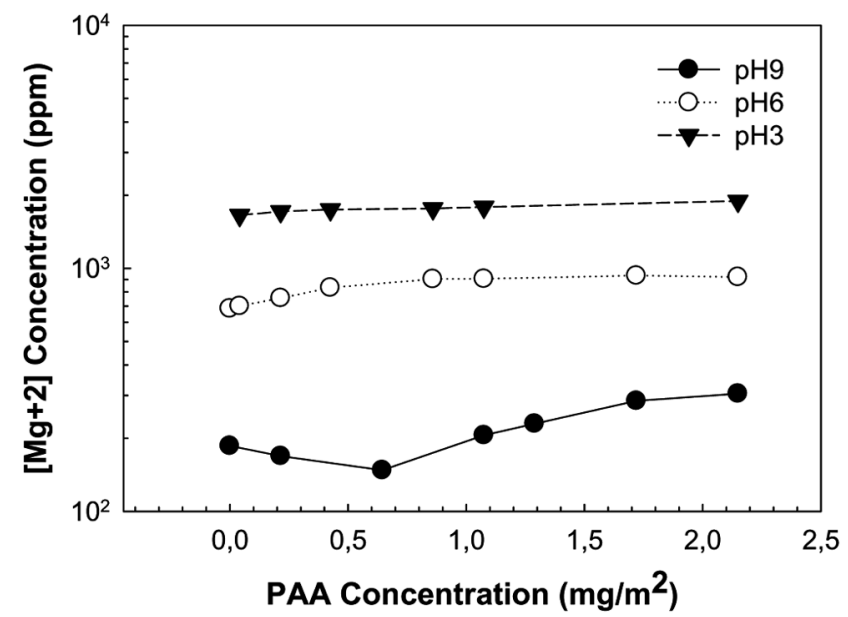

(b)

FIG. 9. Effect of PAA concentration on the leaching of (a) $\mathrm{Pb}^{+2}$ (b) $\mathrm{Mg}^{+2}$ in PMN suspension (10 vol\%) at $\mathrm{pH} 9,6$, and 3 .

the adsorption interaction is strong it is irreversible the polyelectrolytes form a stable passivating layer. In this case surface bound PAA either forms a protecting layer that inhibits the dissolution or complexes with cations in a manner that stabilizes the surface layer and fixes the cations. On the other hand, if adsorption is largely absent due to unfavorable electrostatic interactions then cations will be sequestered only as the ions are released into the solution in accordance with the natural rate of the oxide dissolution. ${ }^{[10]}$

Previously we have investigated the adsorption behavior of PAA and PAA/PEO onto PMN surface. ${ }^{[22]}$ Results indicated that adsorption increases with decreasing $\mathrm{pH}$ for both PAA and PAA/PEO solutions. The adsorption isotherms for PAA at $\mathrm{pH} 3$ was described as high affinity type and characterized by a strong adsorption. In contrast, at $\mathrm{pH} 9$ isotherms correspond to nonhigh affinity type with most of the polymer remaining free in solution. Similarly, 
PAA/PEO comb polymer showed a low affinity adsorption nearly at all $\mathrm{pH}$ values. Results also revealed that for both of the polyelectrolytes under investigation the adsorption amount was slightly higher in the presence of $\mathrm{MgCl}_{2}$. It has shown that in the presence of PAA, addition of $\mathrm{MgCl}_{2}$ increased the adsorption nearly 2.6 times. It is possible to attribute this increase to the complex formation between PAA and $\mathrm{Mg}^{+2}$ ions. On the other hand, the increase in the adsorption of PAA/PEO onto PMN in the presence of monovalent or divalent salt was attributed to the decrease in the electrostatic forces rather than complex formation with the divalent metal ions in solution. ${ }^{[22]}$

Similarly, Vermohlen et al. investigated the effect of $\mathrm{Ca}^{+2}$ on the adsorption of acrylic based polyelectrolytes onto oxide surfaces. It was found that the adsorption is greatly increased by $\mathrm{Ca}^{+2}$ ions. ${ }^{[30]}$ This is because multivalent cations can bind to the carboxyl functional groups of the polyelectrolyte to form PAA-cation complexes ( $\mathrm{R}-\mathrm{COO}-\mathrm{M}^{+2}-\mathrm{OOC}-\mathrm{R}$ ) in solution. This complexation can promote the adsorption by lowering the net charge of the polyelectrolyte or by decreasing the solubility of the complex in solution. ${ }^{[31]}$

Our previous studies showed that cation concentration in PMN suspensions $(10 \mathrm{vol} \%)$ at $\mathrm{pH} 3$ was about 25000 ppm. ${ }^{[21,29]}$ However, results obtained in the current study revealed that $\mathrm{Pb}^{+2}$ concentration is around $12500 \mathrm{ppm}$ in PMN suspensions in the presence of comb polymer under the same conditions. Similarly, $\mathrm{Pb}^{+2}$ concentration is measured to be $13000 \mathrm{ppm}$ in supernatant in the presence of PAA. Therefore, it is possible to conclude that in the presence of polyelectrolytes under acidic conditions cation dissolution from PMN surface is inhibited due to strong adsorption. This behavior also indicates that dissolution is inhibited by the formation of a physical barrier due to the dense adsorbed polymer layer. ${ }^{[10]}$

In the current study, sequestering of $\mathrm{Pb}^{+2}$ and $\mathrm{Mg}^{+2}$ from the PMN surface may be attributed to the weak reversible adsorption of anionic PAA and PAA/PEO comb polymer onto fairly unstable $\mathrm{Pb}^{+2}$ and $\mathrm{Mg}^{+2}$ surface sites at high $\mathrm{pH}$ values. Furthermore, by complexing dissolved cations, PAA enhances the solubility by acting as a $\mathrm{Pb}^{+2}$ and $\mathrm{Mg}^{+2}$ sink in solution.

\section{CONCLUSIONS}

Effect of PAA and PAA/PEO comb polymers on the solubility of PMN in water was investigated in this paper. Results revealed that both dispersing agents enhances the cation dissolution from PMN surface at $\mathrm{pH}$ 9. Sequestering of $\mathrm{Pb}^{+2}$ and $\mathrm{Mg}^{+2}$ from the PMN surface may be attributed to the weak adsorption of anionic PAA and PAA/PEO comb polymer onto fairly unstable $\mathrm{Pb}^{+2}$ and $\mathrm{Mg}^{+2}$ surface sites. On the other hand, a decrease in solubility was observed at $\mathrm{pH} 3$. It was concluded that in the presence of polyelectrolytes under acidic conditions cation dissolution from PMN surface is inhibited due to strong adsorption. Results showed that the cation release from PMN surface is also dependent on the polymer concentration in suspensions.

\section{REFERENCES}

[1] Fengbing, S., Qiang, L., Haisheng, Z., Chunhong, L., Shix, Z., and Dezhong, S. (2004) Mater. Chem. Phys., 83: 135-139.

[2] Swartz, S.L., Shrout, T.R., Schulze, W.A., and Cross, L.A. (1984) J. Am. Ceram. Soc., 67: 311-315.

[3] Beng, Ng, W., Wang, J., Choon, Ng, S., and Gan, L.M. (1999) J. Am. Ceram. Soc., 82: 529.

[4] Blackwood, G.H. and Ealey, M.A. (1993) Smart Mat. Struct., 2: 124-133.

[5] Brailenau, A., Ianculescu, A., Zaharescu, M., Pasuk, I., Preda, S., Madarasz, J., and Pokol, G. (2004) Key Eng. Mater., 1309: 264-268.

[6] Tzou, H.S., Lee, H.J., and Arnold, S.M. (2004) Mech. Advanced Mat. Struct., 11: 367-393.

[7] Windlass, H., Markondeya, P.J., and Balamaran, D. (2001) Colloidal processing of polymer ceramic nanocomposites for integral capacitors. International Symposium on Advanced Packaging Materials Proceedings, 393-398.

[8] Adair, J.H., Crampo, J., Mandanas, M.M., and Suvaci, E. (2006) J. Am. Ceram. Soc., 89: 1853-1860.

[9] Nesbitt, W.H., Bancroft, M.G., Fyfe, S.W., Karkhanis, H.S., and Nishijima, A. (1981) Nature, 289: 358-362.

[10] Paik, U., Hackley, A.V., Lee, J., and Lee, S. (2003) J. Mater. Res., 8: 1266-1274.

[11] Costa, A.L., Galassi, C., Fabri, G., Roncari, E., and Capiani, C. (2001) J. Eur. Ceram. Soc., 21: 1165-1170.

[12] Lewis, J.A. (2000) J. Am. Ceram. Soc., 83: 2341-2359.

[13] Cesarano III, J. and Aksay, I.A. (1988) J. Am. Ceram. Soc., 71: 250-255.

[14] Hackley, V.A. (1997) J. Am. Ceram. Soc., 80: 2315-2325.

[15] Li, C.C. and Jean, J.H. (2002) J. Am. Ceram. Soc., 85: 2977-2983.

[16] Kirby, G.H., Daniel, H., Qi, L., and Lewis, J.A. (2004) J. Am. Ceram. Soc., 87: 181-186.

[17] Kirby, G.H. and Lewis, J.A. (2004) J. Am. Ceram. Soc., 87: 1643-1652.

[18] Şakar-Deliormanlı, A., Çelik, E., and Polat (2008) Viscosity and Zeta Potential of PMN Suspensions in the Presence of Polyelectrolytes, 7th Ceramic Congress with International Participation, Turkey, Proceeding Book, TE177, pp. 616-624.

[19] Kislenko, V.N. and Verlinskaya, R.M. (2002) Colloid J., 64: 498-502.

[20] Zaman, A.A. and Mathur, S. (2004) J. Colloid Inter. Sci., 271: 124-130.

[21] Deliormanlı, A.M., Çelik, E., and Polat, M. (2007) J. Am. Ceram. Soc., 90: 3314-3317.

[22] Şakar-Deliormanlı, A., Çelik, E., and Polat, M. (2008) Colloid Surf. A., 316: 202-209.

[23] Sadar, M.J. (1998) Turbidity Science, Technical Information Series Booklet; Loveland, CO: Hach Co.; vol. 11, pp. 1-18. 
[24] Cohen-Stuart, M.A., Weajen, F.H.L.H., Cosgrove, T., Vincent, B., and Croculey, T. (1984) Macromolecules, 17: 1825-1830.

[25] Netz, R.R. and Andelman, D. (2003) Phys. Reports, 380: 1-95.

[26] Kirby, G.H. (2003) PAA/PEO comb polymer effects on the rheological property evolution in concentrated cement suspensions. Ph.D. Thesis.

[27] Paik, U. and Hackley, A.V. (2000) J. Am. Ceram. Soc., 83: 2381-2384.
[28] Neubrand, A., Lindner, R., and Hoffmann, P. (2000) J. Am. Ceram. Soc., 83: 860-864.

[29] Şakar-Deliormanl1, A., Erdal, Ç., and Polat, M. (2008) Ceram. Int., 35: 503-508.

[30] Vermohlen, K., Lewandowski, H., Narres, H.D., and Schwuger, M.J. (2000) Colloid. Surf. A, 163: 45-53.

[31] Sun, J., Bergstrom, L., and Gao, L. (2001) J. Am. Ceram. Soc., 84: 2710-2712. 